\title{
THE IMPACT OF AWARENESS OF ASSESSIMENT CRITERIA ON PERFORIMANCE OF STUDENTS IN GROUP ACTIVITIES.
}

KEY WORDS:

\section{Dr. Unmesh.A.K*}

\section{Dr. Biju} Bahuleyan
Additional Professor of Forensic Medicine, Govt. Medical College, Ernakulam. *Corresponding Author

Professor of Physiology, Jubilee Mission Medical College \& Research Institute, Thrissur.

Introduction: In higher education, outcome based approach to teaching is the dictum. Assessment criteria should be designed to ensure that learning takes place at the level appropriate to the assigned skill. Students when familiarised with the assessment criteria results in self-motivated approach to attain that skill. The objective of the present study is to determine the impact of awareness of assessment criteria on the performance of students in group activities.

Materials and methods: 100 phase one MBBS students were included in the study. Whole batch was divided into 15 small groups and each group was given a problem based question to discuss. The role of each participant in the group was assessed by assessors using specified assessment criteria. Assessment was done in two phases. In the second phase students were made aware of the assessment criteria. Reflections of students regarding the assessment criteria were also collected.

Results:The scores obtained after the students were aware of the assessment criteria was higher and the difference was found to be statistically significant. Majority of the students reflected on the positive impact of being aware of the assessment criteria.

Conclusion: Knowing about based on what criteria a candidate is being assessed motivates the student to perform better. In activities which was not assessed earlier the approach of using an assessment criteria and making the student aware of it would definitely assure better performance.

\section{INTRODUCTION:}

The process of acquisition of knowledge and skills is a highly debated topic. Educational researchers have explored into this process and designed multiple theories. Any learning process starts with the framing of learning objectives which consists of three main elements -student's action, content and the standard required to meet the objectives (1). Assessment criteria relates to the third part of the element. "Assessment drives learning" is the dictum in any form of education but the lack of proper guidelines in the process of assessment for various skills has resulted in anguish in the student population $(2,3)$.

Assessment criteria are descriptive statements providing information about the qualities, characteristics and aspects of a learning task. The presence of an assessment criterion takes the "guess work" out of the grading process thus allowing the instructors to evaluate the learner more consistently and objectively. It further helps the instructor to justify how marks are being awarded. Group activity forms a major component in the training of medical students' .the importance of team work in a profession like medicine cannot be side-lined. But assessment of these skills are rarely been done and if done no proper strategies are adopted for the same (4). Designing assessment criteria for skills which were not assessed earlier is a major challenge for the teacher and student. to capture the multiple dimensions of a student's performance like work cooperatively, behave ethically, assess and evaluate information and provide helpful feedback needs well designed criteria.

Sharing of assessment criteria with the learner makes them realize what is important in the curriculum and hence focus on the learning objectives and reflect on their performance. Awareness of the factors on the basis of which they would be evaluated leads to the students incorporating these qualities in their group activities and further helps built confidence in their learning process. But the assessment criteria is not shared with the students in majority of the learning institutions resulting in the feeling of sense of unfairness in the assessment process from the student perspective. Awareness of assessment criteria leads to a better quantitative differentiation of performance level as noted by miller.
The present study is designed with the objective of assessing the impact of awareness of assessment criteria in the performance of students in group activities.

\section{MATERIALS AND METHODS:}

The present study was conducted in department of physiology, jubilee mission medical college and research institute. The phase one MBBS students who were willing to participate in the study were taken as the study participants. The study commenced after sanction was obtained from institutional ethics committee.

100 phase one MBBS students were grouped into 15 batches with each batch having six /seven members. This study was conducted in two phases. In first phase a problem based question was given to each team for discussion .Each team had to select a leader for their group who would then assign duties to each member in the team. The group were made aware that they would be assessed regarding their participation in the group activities but the criteria for assessment was not made known to them during this phase of the study. Each team member was assessed using an assessment criteria by assessors. Eight such sessions were conducted and each member in the team played a different role each time.

In second phase of the study all the students were given a preset list of the assessment criteria and the assessors briefed them about each criteria the group activity was done again for eight sessions in this manner.

Assessment criteria included teamwork, time management, communication and interpersonal skills. Based on the performance in each criteria students were graded poor, satisfactory, good and excellent. After the sessions the students were asked to write a reflection about their performance in group activities once they were made aware of the assessment criteria.

\section{Data analysis:}

Scores obtained by each participant was tabulated and mean scores calculated. Comparison of scores obtained before and after awareness of assessment criteria was done using paired 
$t$ test. Frequency distribution of the study participants into excellent, good, satisfactory and poor before and after being made aware of the assessment criteria was also done.

\section{Results:}

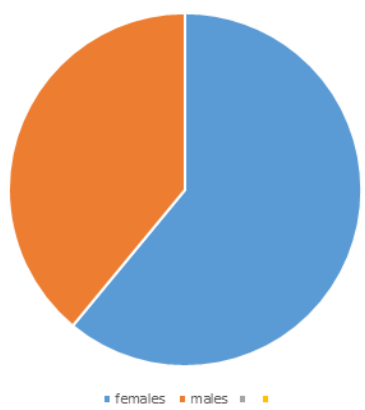

Figure:1. Gender Wise Distribution Of The Study Participants

Table : 1. Mean scores before and after awareness of assessment criteria

\begin{tabular}{|l|l|l|}
\hline & Mean score & P value \\
\hline Before awareness & $11.06+-1.19$ & $<0.001^{*}$ \\
\hline After awareness & $14.97+-2.00$ & \\
\hline
\end{tabular}

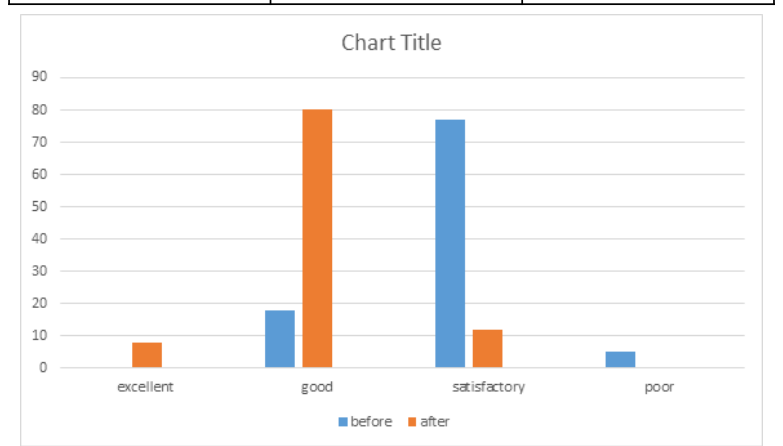

Figure: 2. Frequency distribution of participants into four categories before and after awareness of assessment criteria

\section{DISCUSSION:}

The role of assessment in steering the learning process is well documented in literature. The present study emphasises the importance of making the students aware of the assessment criteria. The level of participation of the students in group activities was assessed twice using a set of assessment criteria. The second phase of assessment was done after the students were made aware of the assessment criteria. The mean scores obtained by the students before was less compared to that obtained after they were made aware of the criteria and this was found to be statistically significant. Students were also grouped into different levels based on their scores. It was found that the initial assessment showed more number of students belonging to the satisfactory performance group while there were no participant belonging to the excellent group. But after being made aware of the assessment criteria more number of students were seen in the good performers' category.

The reflections written by students were also examined and majority of the students were in support of the concept of forming assessment criteria and making them aware about it. Students feel that it also helps them to self-evaluate their contribution to group activities and teamwork skills. Awareness of the assessment criteria made them realise the importance of respectful listening, considering opposing views and effectively managing conflicts. The idea that they would be judged based on these criteria motivated them to successfully incorporate these qualities into their group activities. It also ensures individual accountability in group activities.

Better task performance can be ensured by drawing the attention of the student towards the assessment criteria for that task as noted by Fastre et al(5).The paradigm shift from an instructor led system to a student led system can be successful only by familiarizing the students with the assessment criteria. Ecclestone also highlighted that when students know what criteria is used to assess them their motivation, learning and performance is bound to increase significantly.

\section{CONCLUSION:}

What to learn and how to learn depends to a large extend on how the students think they will be assessed. For skills which were never assessed like participation in group activities the presence of an assessment criteria, familiarising the students with the criteria ensures better performance in group activities.

\section{REFERENCES:}

1. The office of learning and teaching, 2004. Melbourne: Department of education and training; oecd, 2010. Nature of learning, Paris: author; http://www.p21.org/

2. Khalil MK, Lamar CH, Johnson TE. Using computer-based interactive imagery strategies for designing instructional anatomy programs. Clin Anat. 2005 jan;18(1):68-76.Doi: 10.1002/ca.20049.pmid: 15597366

3. Benjamin W Wormald ${ }^{1}$, Scarpa Schoeman, Arnold Somasunderam, Michelle Penn. Assessment drives learning: an unavoidable truth? Aanat Sci Educ.2009 oct;2(5):199-204.

4. Yedidia MJ, Gillespie CC, Kachur E, Schwartz MD, Ockene J, Chepaitis AE, et al. Effect of communications training on medical student performance. Jama. 2003;290:1157-65

5. Greet Fastré, Marcel R Van Derklink. The effects of performance-based assessment criteria on student performance and self-assessment skills. Advances in health sciences education 15(4):517-32 Doi: 10.1007/s10459009-9215-x

6. Kathryn Ecclestone, John Pryor. 'Learning careers' or 'assessment careers'? The impact of assessment systems on learning. British Educational Research Journal.https://doi.org/10.1080/01411920301849. 